\title{
In reply: preventing aspiration during peroral endoscopic myotomy
}

\author{
Hiroaki Murata $\cdot$ Eriko Tanaka $\cdot$ Hitomi Minami
}

Received: 22 August 2014/ Accepted: 25 August 2014/Published online: 29 October 2014

(C) Japanese Society of Anesthesiologists 2014

To the Editor:

We thank Dr. Saxena and colleagues for their constructive comments on our report [1]. Although we emphasized the importance of avoiding aspiration during anesthesia induction, we agree that the prevention of aspiration is also important during the peroral endoscopic myotomy (POEM) procedure.

In our report [1], esophagoscopy after anesthetic induction showed that no contents remained. However, as Dr. Saxena et al. mentioned, esophageal irrigation fluid can regurgitate into the pharynx when the tone of the lower esophageal sphincter remains high. Indeed, we repeatedly suction subglottic fluid through the suction channel of the endoscopy whenever it is drawn back from the esophagus during the POEM procedure. This technique has resulted in no clinically apparent perioperative aspiration in 78 POEM patients at our institute. An advantage of the tracheal tube with a supra-cuff evacuation port and a suction lumen is that subglottic fluid can be removed continuously, independent of the POEM procedure. A taper-shaped cuff instead of the cylindrical high volume low pressure cuff that we used can also reduce micro-aspiration.

POEM is becoming popular as a therapeutic option for achalasia [2]. Accumulating knowledge concerning safer perioperative management of POEM is important to establish POEM as a consolidated treatment modality.

Conflict of interest There is no conflict of interest.

\section{References}

1. Tanaka E, Murata H, Minami H, Sumikawa K. Anesthetic management of peroral endoscopic myotomy for esophageal achalasia: a retrospective case series. J Anesth. 2014;28:456-9.

2. Minami $H$, Inoue $H$, Haji $A$, Isomoto $H$, Urabe $S$, Hashiguchi $K$, Matsushima K, Akazawa Y, Yamaguchi N, Ohnita K, Takeshima F, Nakao K. Per-oral endoscopic myotomy: emerging indications and evolving techniques. Dig Endosc. 2014. doi:10.1111/den. 12328.

\footnotetext{
H. Murata $(\bowtie) \cdot$ E. Tanaka

Department of Anesthesiology, Nagasaki University School

of Medicine, Nagasaki, Japan

e-mail: h-murata@nagasaki-u.ac.jp

H. Minami

Department of Gastroenterology and Hepatology,

Nagasaki University School of Medicine, Nagasaki, Japan
} 